\title{
Effect of Personal Values Similarity on B2B Relationship Value
}

\author{
Thayane Manosso ${ }^{1}$ \\ thay_thay3@hotmail.com | (D) 0000-0002-9932-5520 \\ Juliano Silva ${ }^{2}$ \\ jdomingues8@gmail.com | (D) 0000-0001-7599-0617 \\ Verner Antoni ${ }^{1}$ \\ antoni@upf.br | (DD 0000-0002-7780-6470 \\ Claudio Damacena ${ }^{3}$ \\ damacena.claudio@gmail.com | (D) 0000-0002-8331-9302
}

\begin{abstract}
Similarity of values influences the relationship between companies. However, even if organizational decisions are made by people, the role played by similarity of personal values for those involved in the trade is little explored in the B2B context. Based on the similarity-attraction theory, we developed a model that explores the effect that similar of personal values between buyer and seller has in the B2B relationship value. Using a sample composed of 25 sellers and 317 buyers, we tested the hypotheses by means of polynomial regression with a response surface analysis. The results demonstrate that similarity of personal values, in regards to a social focus, between seller and buyer has a positive effect on the B2B relationship value. However, when individuals are more similar relation to personal values, the lower value the buyer perceives in the relationship with his provider. The paper also addresses implications for the theory, and B2B management theory. Relationship Implications
\end{abstract}

\section{KEYWORDS}

Values Similarity, Personal Values, B2B Relationship, Relationship Value
${ }^{1}$ Universidade de Passo Fundo, Passo Fundo, RS, Brasil

${ }^{2}$ Universidade Estadual de Maringá, Maringá, PR, Brasil

${ }^{3}$ Universidade de Santa Cruz do Sul, Santa Cruz do Sul, RS, Brasil

Received: 04/08/2020.

Revised: 06/29/2020.

Accepted: 07/14/2020.

Published Online: 03/15/2021.

DOI: http://dx.doi.org/10.15728/bbr.2021.18.3.3 


\section{INTRODUCTION}

Decisions in business-to-business (B2B) markets are made by people, not by organizations. The ultimate decision-making authority typically resides in a single individual or small executive group (Grewal et al., 2015). Researchers engaged in studying the micro context of interorganizational relationships investigate how the characteristics of members of the organizations impact the functioning and results of the B2B relationships (Cropper et al., 2014).

In general, the literature shows that individuals can have their own goals and experiences, which can affect their behavior and, consequently, influence relationships between companies (Manosso \& Antoni, 2018; Torres et al., 2016). Among the fundamentals often used to predict behaviors, trends and individual choices are examples of personal values ( $\mathrm{Qu}$ et al., 2017; Torres et al., 2016). Personal values are deep and powerful motivators of social actions, and represent an organizing principle, not just in personal life, but also in the organizations into which individuals are inserted (Byza et al., 2019). Schwartz's (1992) structural approach to human values is shown as one of the main contemporary references on the topic, used in research to understand human behavior (Torres et al., 2016).

Just as personal values guide individuals decisions, it is believed that another type of value determines the success of interorganizational relationships: the relationship value (Ulaga \& Eggert, 2006). From a unidirectional perspective, the value perceived by the customer is seen as a trade-off between benefits and sacrifices in relation to the relationship with a supplier, taking into account the alternative offers available (Eggert \& Ulaga, 2002).

The similarity-attraction theory (Byrne, 1971) indicates that, in order to achieve a higher level of value in the relationship, there must be significant similarity on the part of the partners, and that buyers can perceive different levels of value when evaluating the supplier as a whole, as well as an individual (e.g., manager, salesperson) that symbolizes this supplier company (Lilien, 2016; Alejandro et al., 2011). Although this notion of the importance of similar values is ubiquitous in research at an individual level (e.g., Edwards \& Cable, 2009), surprisingly, as far as we understand , research at an interorganizational level focuses only on the effects generated by the similarity between organizational values (e.g., Wang \& Zhang, 2017; Kashyap \& Sivadas, 2012), ignoring how personal values similarity between buyer andseller can impact the perceived relationship value (see Table 1).

We believe that this gap is worrying for two reasons. First, since decision making at the organizational level ultimately falls to the decision making of an individual (or small group of individuals), the scarcity of research on the impact of human values on the relationship between companies makes our view limited about B2B relationships (Zhu \& Chang, 2013). This limitation restricts the $\mathrm{B} 2 \mathrm{~B}$ relationship marketing literature from providing more accurate insights to improve relationships between companies.

Second, there is still no consensus among researchers about the antecedents, moderators or consequences of the relationship value (Arslanagic-Kalajdzic \& Zabkar, 2015; Hohenschwert $\&$ Geiger, 2015), nor about the effect of similar values values similarity between individuals on the B2B relationship. (He et al., 2018). As Skarmeas et al. (2018, p. 280) highlights, "a relatively small number of studies investigate the role of the relationship value in interorganizational relationships". In this sense, this research can shine a light on this theme, since our proposal seeks to investigate how similar values between individuals impacts the B2B relationship value. The literature provides consistent evidence that salespeople are crucial to creating value, as they are in a prominent position to understand customer value drivers, communicate the value propositions, and provide customer insights to the company (Blocker et al., 2011). For Alejandro 
et al. (2011), the role and relevance of those responsible for direct contact with the client justifies further examination. We present the research gap in Table 1.

Given this scenario, the objective proposed by this study is to evaluate the effect of potential similarities in the personal values of sellers and buyers on the B2B relationship value. We collected data on human values on both sides of the dyad (sellers-buyers) to obtain the values similarity between both; and, subsequently, we evaluated the effect of this similarity on the value perceived by the buyer in the relationship with the supplier company. Data was obtained from 317 farmers (buyers) and 25 salespeople from a retailer of agricultural inputs, machines and implements (sellers). To provide robustness to our analysis, we used polynomial regression with a response surface analysis (Edwards \& Parry, 1993). Although this analysis has a high degree of precision when performing simultaneous tests of effects, its use does not seem common in research regarding similar values, as shown in Table 1.

This research contributes to the literature on B2B relationship marketing since the current literature considers only organizational values and not the personal values of the people involved in the commercial exchanges between companies. Therefore, researchers often say that it is beneficial to have a business partner with similar values. This study shows that, when it comes to personal relationships, it is not always advantageous for the seller to have similar personal values as their buyer, as this can cause friction in the relationship. Our study also contributes to the similarityattraction theory (Byrne, 1971), by showing that only the similarity between socio-personal values of the individuals involved in B2B exchanges improves the B2B relationship. Personal values are likely to impair the perceived relationship value by generating conflict between the parties.

As a practical contribution, we show how important it is to get to know buyers before providing a seller to serve them, and which traditional segmentation means can be improved, while also taking into account the profile of the buyer's market and the sales team. In addition, the importance of the constant search for the creation and maintenance of the value that the buyer perceives in the relationship with their supplier is highlighted, and the crucial role that the seller has in this perception.

\section{THEORETICAL BACKGROUND}

\subsection{Personal values}

Human, individual, or personal values can be defined as "a lasting belief that a specific mode of conduct or final state of existence is personally or socially preferable to an opposite or reverse mode of conduct or final state of existence" (Rokeach, 1973, p. 5). Values provide individuals with a kind of criterion for choosing and justifying actions and evaluating people and events (Schwartz, 1992). For Schwartz et al. (2012), personal values are beliefs or ideas about what is desirable in a given context and situation. An individual's basic value system does not change easily and can be used to direct the activities of market-oriented companies (Schwartz, 1992; Rokeach, 1973).

Schwartz's (1992) theory of human values, based on Rokeach's (1973) original propositions, is considered to be the main contemporary reference on the subject. In order to expand the heuristic capacity and the predictive and explanatory power of the theory, Schwartz et al. (2012) presented a refined version, as well as a new instrument for measuring personal values, the PVQRefined (PVQ-RR), which divides the continuum into a finer set of nineteen values, which are conceptually distinct (Schwartz et al., 2012) The study by Torres et al. (2016) translated and 
validated the PVQ-RR in the context of Brazilians, in addition to testing the usefulness and validity of the predictive power of the 19 values for behavior.

Schwartz et al. (2012) presented a refined theory of personal values in which two broader underlying categories were identified: social focus values (Self-transcendence and Conservation), which indicate concern for results for others or for established institutions; and personal focus values (Openness to change and Self-promotion), which reflect concern for results for oneself (Schwartz et al., 2012). Although personal values are reliable predictors of human behavior, and organizational decisions are made by people, individual values are hardly incorporated into B2B relationship research.

\subsection{Similarity-attraction theory and Values Similarity}

When postulating the similarity-attraction theory, Byrne (1971) proposes the paradigm that higher levels of similarity between individuals generates positive affection and increased attraction and harmony. . The more similar, the greater the preference for similar parts and the desire to interact with these parts is more frequent (Byrne, 1971).

When explaining the mechanisms of the similarity-attraction theory, Cable and Edwards (2004) highlight that people have difficulty in dealing with what is different and, for this reason, they tend to approach and prefer individuals who judge and act in a similar way to them. Thus, the similarity between individuals tends to be beneficial in the relations between companies, since the greater the similarity between the people representing the organizations, the better the resolution of problems together and the higher the satisfaction with the decisions made by the other (Wilson et al., 2016). On the contrary, dissimilarity alienates people, making them more prone to conflicts and social distancing, which can impair the performance of companies involved in B2B relationships (Cable \& Edwards, 2004).

The benefits of values similarity occur because of a supplementary adjustment in which two individuals "share similar fundamental characteristics" (Verquer et al., 2003, p. 474). The values similarity between partners tends to generate positive perceptions of the relationship, because both share common aspects of cognitive processing and common methods of interpreting events, which helps to reduce uncertainty and conflict in their interactions (Ostroff et al., 2005).

Palmatier et al. (2006) highlights that similarity can be measured between individuals or between organizations. Given the importance of values for organizations, the literature commonly examined the relationship between organizational values and employee values (Byza et al., 2019; Arieli et al., 2020), values between customers and brands (Krystallis et al., 2012) and the impact of the congruence of leaders and their team with their values on the performance of organizations ( $\mathrm{Qu}$ et al., 2017). Although research shows that similar values between members of a commercial exchange has a positive effect on the relationship between buyer and supplier (Kashyap \& Sivadas, 2012), the potential effects of personal values similarity on B2B exchanges is still little explored (Wang \& Zhang, 2017).

\subsection{Relationship Value}

Value, from the customer's perspective, can be defined as the "trade-off between the multiple benefits and sacrifices of a supplier's offer, as perceived by the main decision makers in the customer's organization, and taking into account the offers available from alternative suppliers" (Eggert \& Ulaga, 2002). Customer value surveys followed the transition of the marketing discipline, adopting the definition of "relationship value", previously known as and still commonly called customer value or perceived value (Eggert et al., 2006). 
According to Ulaga and Eggert (2006), the relationship value has a significant and positive effect on customer satisfaction, which, consequently, increases the likelihood of business retention and positive word of mouth. Likewise, Arslanagic-Kalajdzic and Zabkar (2015) state that the perception of value in the relationship with a supplier helps to form attitudinal and behavioral results for the customer and influences the performance of the supplier, which are reflections of the customer's loyalty and repurchase. As for Alejandro et al. (2011), people seem to perceive greater value in a relationship when they evaluate an individual, and not an organization.

Some authors have used, among other constructs, relationship value to measure the success and quality of B2B relationships (Arslanagic-Kalajdzic \& Zabkar, 2015; Skarmeas et al., 2018). Even so, it is believed that value has not received its due attention in B2B relationship research, considering that providing value to the customer is essential to creating and maintaining longterm relationships (Skarmeas et al., 2018; Ulaga \& Eggert, 2006). As previously highlighted, this research seeks to fill the gap in the B2B relationship marketing literature by examining the effects of the personal values similarity between business partners on the relationship value, as shown in Table 1.

Table 1

Literature related to the personal values similarity in $B 2 B$ contexts and the relationship value

\begin{tabular}{|c|c|c|c|c|c|}
\hline Authors & $\begin{array}{l}\text { Values Similarity } \\
\text { between... }\end{array}$ & $\mathrm{B} 2 \mathrm{~B}$ & $\begin{array}{l}\text { Human } \\
\text { Values }\end{array}$ & $\begin{array}{l}\text { Relationship } \\
\text { Value }\end{array}$ & $\begin{array}{c}\text { Polynomial } \\
\text { Regression and ASR }\end{array}$ \\
\hline Zhang \& Bloemer (2008) & Consumers and Brand & & $\sqrt{ }$ & & \\
\hline Kashyap \& Sivadas (2012) & Channel Companies & $\sqrt{ }$ & & & \\
\hline Sabbir \& Nazrul (2014) & Clients and Organization & & $\sqrt{ }$ & & \\
\hline Qu et al. (2017) & Employees and Leaders & & $\sqrt{ }$ & & \\
\hline Wang \& Zhang (2017) & Suppliers and Distributors & $\sqrt{ }$ & & & \\
\hline He et al. (2018) & Buyers and Brand & $\sqrt{ }$ & & & \\
\hline Byza et al. (2019) & Employees and Leaders & & $\sqrt{ }$ & & $\sqrt{ }$ \\
\hline This study & Sellers and Buyers & $\sqrt{ }$ & $\sqrt{ }$ & $\sqrt{ }$ & $\sqrt{ }$ \\
\hline
\end{tabular}

Source: Developed by the authors.

\subsection{THEORETICAL MODEL AND RESEARCH HYPOTHESES}

First, according to the similarity-attraction paradigm (Byrne, 1971) we suggest that values of social focus (Self-transcendence and Conservation) positively impact the relationship value.

Specifically, the Self-transcendence dimension indicates the change of one's interests for the benefit of others, and includes values such as concern for the well-being, loyalty, and dependence of people with whom frequent personal contact is maintained, as well as values of tolerance and social equality (Schwartz, 1992; Schwartz et al., 2012). These values, inherent to Self-transcendence, highlight an individual's preference for privileging social focus values, in which collective aspects are important (Schwartz et al., 2012). Thus, considering a B2B relationship in which the seller and buyer report high self-transcendence, we expect the buyer to evaluate their relationship with the seller as being valuable. Formally: 
- H1. In similarity situations, the Relationship value will be higher when the Buyer's Self-Transcendence is high and the Seller's Self-Transcendence is high.

It is also important to distinguish between the two scenarios of dissimilarity between the values, that is, when the buyer's Self-transcendence is greater than that of the seller or vice versa. If the Self-transcendence values are dissimilar, it is expected that the relationship value will be higher when the buyer's self-transcendence is high and that of the seller is low.

In the scenario where the buyer has greater Self-transcendence than the seller, the buyer's willingness to develop loyalty and dependency in relationships (Schwartz et al., 2012) is likely to make this buyer realize that the relationship with the seller is valuable, even if the seller is not reciprocal in respect to Self-transcendence. However, if the seller expresses high values of Self-transcendence in the relationship with the buyer, but the buyer does not share those same values (i.e., low Self-transcendence of the buyer), the buyer is likely to not validate his or her prospects of value in the interaction with the seller, reducing his/her perception of relationship value. Thus, we propose the following hypothesis:

- H2. In dissimilarity situations, the Relationship value will be higher when the Buyer's Self-Transcendence is high and the Seller's Self-Transcendence is low.

Conservation is also a dimension of social focus, which represents self-restraint, order, and avoiding changes. It encompasses personal values that represent an individual's sense of belonging, the importance of having others care about him/her, as well as values of concern for social security, compliance with rules and obligations, courtesy, respect, doing what is right, and respecting traditions, for example (Schwartz et al., 2012). Therefore, in situations of similarity, conservative buyers are expected to perceive greater value in the relationship if the seller also has high Conservation values. Formally:

- H3. In similarity situations, the Relationship value will be higher when the Buyer's level of Conservation is high and the Seller's level of Conservation is high.

In dissimilarity scenarios, we expect the relationship value to be higher when the buyer has a high level of Conservation and the seller has a low level of Conservation. In line with the arguments described in the previous hypothesis, we believe that the buyer's Conservation values make him or her want to maintain the status quo of the relationship with the seller, regardless of whether the seller has a low sense of Conservation. However, if the seller shows high Conservation and the buyer low Conservation, these buyers may not fulfill their perspectives on the relationship, reducing their perception of its value. Thus, we propose the following hypothesis:

- H4. In dissimilarity situations, the Relationship value will be higher when the Buyer's level of Conservation is high and the Seller's level of Conservation is low.

Second, personal focus values involve an individual's concern about the results for themselves (Schwartz et al., 2012). Thus, individuals with high levels of personal values tend to value relationships that provide opportunities for self-improvement, that is, relationships that improve or reinforce self-concept (Sirgy, 1982). 
Specifically, the Openness to Change reflects the readiness for new ideas, actions, and experiences. Autonomy to think and act, search for individual purposes, curiosity, own decisions, yearning for novelties and emotions, taking risks, and pleasure are some of the values related to Openness to change (Schwartz et al., 2012). These personal motivations are the result of the need to express self-concept (i.e., individuality). For this reason, we believe that the similarity-attraction paradigm does not apply to personal focus values (i.e., Openness to change and Self-promotion). In a relationship in which buyers and sellers are highly open to change, the need to express individuality can generate conflict in the relationship, since both seek to be competent and skilled in meeting other people (Lalwani \& Shavitt, 2009). Thus, in situations where both the buyer and the seller are highly open to change, the buyer is likely to report that there is less value in the relationship. Formally:

- H5. In similarity situations, the Relationship value will be lower when the Openness to change in the buyer is high and the Openness to change in the seller is high.

In dissimilarity situations, we believe that the relationship value will be greater when the openness to change of the buyer is high and that of the seller is low. Buyers with great openness to change seek relationships that favor experiences to express their individuality (Schwartz et al., 2012) and sellers with low openness to change do not offer a point of conflict for the self-improvement of the buyer. However, in situations where the seller has a high level and the buyer has a low level of Openness to change, the buyer can interpret that the search for self-improvement of the seller during the relationship is a sign of a threat, since people with high openness to change can be narcissistic or individualistic (Schwartz et al., 2012; Campbell et al., 2000). Thus, if the values of Openness to change are dissimilar, it is expected that the relationship value will be greater when the openness to change of the buyer is high and the seller is low. Thus, we propose the following hypothesis:

- H6. In dissimilarity situations, the Relationship value will be higher when the Openness to change in the buyer is high and the Openness to change in the seller is low.

The second dimension of personal focus is Self-Promotion. Values that involve having power over things and over others, prestige, material wealth, social influence, status, being someone that is admired, concern for one's public image, success (according to society's standards) and demonstration of skills represent Self-promotion (Schwartz et al., 2012).

In line with the Openness to change argument, we believe that in situations of similarity between Self-promotion in the relationship of buyer and seller, the relationship value will be perceived as less valuable to the buyer. Thus, the search to express power, prestige, status and admiration of people with high Self-promotion (Schwartz et al., 2012) can generate conflict in the relationship if these motivations are simultaneous for buyers and sellers, that is, when both present high Self-promotion. Formally:

- H7. In similarity situations, the Relationship value will be lower when the Buyer's level of Selfpromotion is high and the Seller's level of Self-promotion is high. 
In dissimilarity scenarios, if the Buyer's Self-promotion is high and the Seller is low, the seller will not offer a sign of possible conflict with the buyer's motivations, therefore, it will not negatively affect the relationship value. However, if the seller's Self-promotion is high, his motivation to express power, status, prestige and admiration can send a sign of arrogance to the buyer who has low Self-promotion (Schwartz et al., 2012; Campbell et al., 2000), reducing the buyer's perceived relationship value. Based on this argument, we propose the following hypothesis:

- H8. In dissimilarity situations, the Relationship value will be higher when Self-promotion in the buyer is high and the Openness to change in the seller is low.

In Figure 1 we illustrate our research hypotheses.

Prediction variables

Result variable

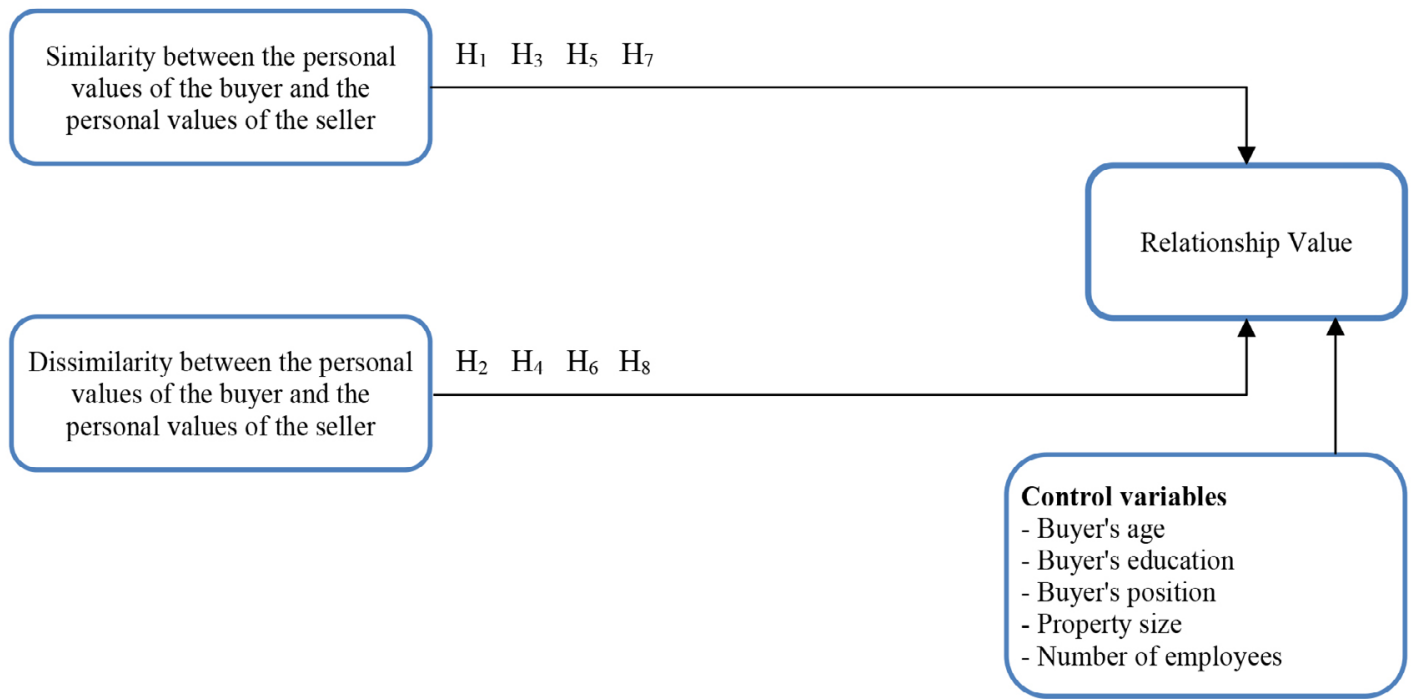

Figure 1. Proposed theoretical model

Source: Developed by the authors.

\section{METHOD}

Data Collection. We applied our research to a retailer of agricultural inputs, machines, and implements, which has six branches located in the southern region of Brazil. To analyze the personal values similarity, data was collected from both sides of the dyad: from the sellers and the buyers (farmers). The sample selection of salespeople was random, and all 27 salespeople answered the questionnaire. The sample of buyers was non-random for convenience, and collected by the salespeople themselves, who received adequate training to perform it. In total, 342 farmers answered the questionnaires. After the treatment of missing data and atypical observations (Hair et al., 2009), the final samples were composed of 317 farmers and 25 salespeople.

Measurement of the variables. We used the Schwartz et al. (2012) Personal Values scale, the PVQRR, translated and validated in Brazil by Torres et al. (2016), which consists of 57 descriptions in which the respondent indicates his resemblance to the individual described on a six-point Likert scale, being 1 "It doesn't resemble me at all" and 6 "It resembles me a lot". We used the 
Relationship Value scale by Alejandro et al. (2011), composed of 5 items and a six-point Likert scale, where 1 corresponds to "I totally disagree" and 6 to "I totally agree".

Control variables. Knowing that farmers have personal and organizational characteristics (Prado \& Martinelli, 2018), we collected data on age, education level, respondent's position, the size (in hectares) of the farm, and the number of employees on the rural property.

Statistical analysis. As the relationship and personal value scales are already validated in Brazil and in the B2B context, a confirmatory factor analysis (CFA) was performed for both scales. Personal values were verified through multidimensional scaling (MDS), as recommended by Torres et al. (2016). The variables also passed through the sieve of normality and multicollinearity (Hair et al., 2009).

To evaluate the effect of personal values similarity on the relationship value, the polynomial regression technique with a response surface analysis (ASR) was used (Edwards \& Parry, 1993). Polynomial regression with response surface testing allows for comparing the effects of two variables in four different scenarios in the same equation: (1) X and Y high, (2) X and Y low, (3) X high and Y low, and (4) X low and Y high. This procedure prevents the use of different scores, since difference scores generate misleading results (Edwards \& Parry, 1993). Details of the equations are described in Appendix A. For an in-depth review and the analysis procedures, see Faia et al. (2019).

\section{RESULTS}

In the sample of salespeople, less than $20 \%$ have been with the company for more than 8 years and the overall average working time is 6.32 years $(\sigma=6.81)$. The average age was 38 years old $(\sigma=11.4)$ and the dominant level of education was the completion of high school. The hierarchy of the dimensions of personal values in the sample of salespeople followed this order: Conservation $(\bar{x}=5.02)$; Self-transcendence $(\bar{x}=4.86)$; Openness to Changes $(\bar{x}=4.61)$; and Self-promotion $(\bar{x}=4.11)$.

As for the organizational characteristics of buyers, only one case (.3\%) had more than 10 employees and the average area of rural properties was 243.38 hectares (ha). As for personal characteristics, $59 \%$ of respondents were partners/owners of the farms and 33\% were the children of the owners. The average general age was 41.32 years old $(\sigma=13.02)$, and $79 \%$ had completed high school.

Regarding the validation of the constructs, the Relationship Value scale obtained AVE = .674 and $\mathrm{CR}=.839$, which configures the convergent validity of the model, and MSV $=.616$, validating the discrimination of factors. The model's adjustment measures were also proven to be adequate: $\mathrm{CMIN} / \mathrm{DF}=2.636(p=.005)$; CFI $=.995 ; \mathrm{GFI}=.992 ; \mathrm{RMSEA}=.72$; and $\alpha=.825$.

The validation of personal values followed the model presented by Torres et al. (2016), where the authors performed the CFAs of each dimension separately. This procedure provides better indexes of adjustment in situations where there is a wide set of latent factors (Torres et al., 2016), as is the case of the PVQ-RR. The adjustment coefficients obtained from the resulting models, by type of second order are shown in Table 2 . 
Table 2

Adjustment coefficients of personal values, by second order types

\begin{tabular}{lcccc}
\hline & Self-transcendence & Conservation & $\begin{array}{c}\text { Openness } \\
\text { to Change }\end{array}$ & Self-promotion \\
\hline CMIN/DF & 2.907 & 2.622 & 2.245 & 2.683 \\
CFI & .906 & .900 & .954 & .930 \\
GFI & .914 & .913 & .955 & .939 \\
RMSEA & .075 & .069 & .060 & .070 \\
$\alpha$ & .847 & .865 & .779 & .778 \\
\hline
\end{tabular}

Source: Developed by the authors.

The MDS is, in turn, configured the ordering of the 19 values, with a stress index- $1=.125$, $\mathrm{DAF}=.985$ and TCC $=.992$. The adjustment coefficients obtained from the resulting models, by type of second order, presented CFI $>.90, \mathrm{GFI}>.90$ and RMSEA $<.08$.

Table 2 shows the results of the regressions, where the dependent variable is the Relationship value and the independent variables are the similarity and dissimilarity between each of the four dimensions of personal values (Self-transcendence, Conservation, Openness to change and Self-promotion) separately. First, the data shows that no control variable directly affects the relationship value. In other words, the relationship value does not vary according to the buyer's age, education, title, size of property, or number of employees.

In the analysis of direct effects, we show that the relationship value is positively influenced by the Self-transcendence $(\beta=.40 ; \mathrm{p}<.01)$, Conservation $(\beta=.38 ; \mathrm{p}<.01)$ and Openness to change $(\beta=.26 ; \mathrm{p}<.01)$ of the buyer. Furthermore, we show that two dimensions of the seller's personal values, Openness to change $(\beta=-.14 ; p<.01)$ and Self-promotion $(\beta=-.39 ; p<.01)$ negatively impact the relationship value. Although we have not elaborated hypotheses of direct effects, these positive effects of the buyer and negative effects of the seller are consistent with our argument of social focus values and personal focus.

To ascertain the similarity effects, we can see in Table 3 , the slope coefficients $\left(a_{1}\right)$ and the curvature coefficients $\left(a_{2}\right)$ of the symmetry line $(\mathrm{X}=\mathrm{Y})$. To ascertain the dissimilarity effects, we can see the slope coefficients $\left(a_{3}\right)$ and the curvature coefficients $\left(a_{3}\right)$ of the asymmetry line $(\mathrm{X}=\mathrm{Y})$.

As shown in Table 3, we found that there is a positive and significant slope along the similarity line on the response surface for Self-transcendence $\left(a_{1}: .34 ; \mathrm{p}<.01\right)$ and Conservation $\left(a_{1}: .30\right.$; $\mathrm{p}<.01)$. Therefore, when the values of Self-transcendence and Conservation are high for both buyers and sellers, the relationship value perceived by the buyer will be greater, supporting hypotheses $\mathbf{H}_{1}$ and $\mathbf{H}_{3}$. When analyzing the symmetry line, we also found that there is a negative and significant slope on the response surface for Self-promotion $\left(a_{1}:-.32 ; \mathrm{p}<.01\right)$ and a nonsignificant inclination for Openness to change $\left(a_{1}: .11 ; n s\right)$ in the relationship value. These results allow for the rejection of $\mathrm{H}_{5}$ and supports $\mathrm{H}_{7^{\circ}}$.

The asymmetry line in Table 3 shows the effects of the dissimilarity between the personal values of the buyers and the personal values of the sellers. The asymmetry line shows that Selftranscendence $\left(a_{3}: .46 ; \mathrm{p}<.01\right)$ and Conservation $\left(a_{3}: .47 ; \mathrm{p}<.01\right)$, Open to changes $\left(a_{3}: .40 ; \mathrm{p}<\right.$ $.01)$ and Self-promotion $\left(a_{3}: .50 ; \mathrm{p}<.01\right)$ have positive and significant effects on the relationship value. As the asymmetry line $a_{3}$ is a product of the subtraction of the coefficients $b_{1}$ (personal values of buyers) and $b_{2}$ (personal values of sellers), the positive values indicate the dissimilarity in scenarios where the personal values of the buyers are higher than the personal values of the sellers. These results support hypotheses $\mathbf{H}_{2}, \mathbf{H}_{4}, \mathbf{H}_{6}$ e $\mathbf{H}_{8}$. 
BBR

18

288

Table 3

Results of the polynomial regressions by dimension of personal value

Dependent variable $=$ Relationship Value

\begin{tabular}{|c|c|c|c|c|}
\hline & & & & \\
\hline & Self-transcendence & Conservation & $\begin{array}{l}\text { Openness to } \\
\text { change }\end{array}$ & Self-promotion \\
\hline Variable & $\beta$ (t-value) & $\beta$ (t-value) & $\beta$ (t-value) & $\beta$ (t-value) \\
\hline Constant & $-.07(-.94)$ & $-.02(-.29)$ & $-.06(-.76)$ & $-.05(-.60)$ \\
\hline Personal values of the buyers $\left(b_{1}\right)$ & $.40(6.17)^{* *}$ & $.38(5.55)^{* *}$ & $.26(4.13)^{* *}$ & $.08(1.05)$ \\
\hline Personal values of the sellers $\left(b_{2}\right)$ & $-.07(-1.19)$ & $-.08(-1.38)$ & $-.14(-2.67)^{* *}$ & $-.39(-5.99)^{* *}$ \\
\hline Personal values of the buyers ${ }^{2}\left(b_{3}\right)$ & $.01(.16)$ & $.03(.75)$ & $.03(.83)$ & $.08(1.23)$ \\
\hline $\begin{array}{l}\text { Personal values of the sellers } x \text { Personal } \\
\text { values of the buyers }\left(b_{4}\right)\end{array}$ & $.06(.99)$ & $.06(.92)$ & $.10(1.99)^{*}$ & $-.03(-.46)$ \\
\hline Personal values of the sellers ${ }^{2}\left(b_{5}\right)$ & $.06(1.46)$ & $-.01(-.3)$ & $.01(.23)$ & $-.11(-2.31)^{*}$ \\
\hline \multicolumn{5}{|l|}{ Control variables } \\
\hline Buyer's age & $-.06(-.90)$ & $-.09(-1.39)$ & $-.03(-.52)$ & $-.06(-.91)$ \\
\hline Buyer's education & $.04(.61)$ & $.05(.85)$ & $.02(.27)$ & $.04(.56)$ \\
\hline Buyer's position & $-.05(-.90)$ & $-.07(-1.19)$ & $-.05(-.89)$ & $-.04(-.78)$ \\
\hline Property size & $.08(1.34)$ & $.03(.56)$ & $.06(.96)$ & $.05(.76)$ \\
\hline Number of employees & $.01(-.08)$ & $.02(.38)$ & $.02(.30)$ & $.06(1.03)$ \\
\hline \multicolumn{5}{|l|}{ Response surface test } \\
\hline \multicolumn{5}{|l|}{ Symmetry line $\mathrm{X}=\mathrm{Y}$} \\
\hline Inclination $\left(a_{1}\right)$ & $.34^{* *}$ & $.30^{* *}$ & .11 & $-.32^{* *}$ \\
\hline Curvature $\left(a_{2}\right)$ & $.13^{*}$ & .08 & $.14^{*}$ & -.06 \\
\hline \multicolumn{5}{|l|}{ Asymmetry line $\mathrm{X}=-\mathrm{Y}$} \\
\hline Inclination $\left(a_{3}\right)$ & $.47^{* *}$ & $.46^{* *}$ & $.40^{* *}$ & $.50^{* *}$ \\
\hline Curvature $\left(a_{4}\right)$ & -.01 & -.05 & -.06 & .01 \\
\hline $\mathrm{VIF}^{\mathrm{a}}$ & 1.56 & 2.20 & 1.47 & 3.77 \\
\hline$R^{2}$ & .18 & .15 & .08 & .14 \\
\hline
\end{tabular}

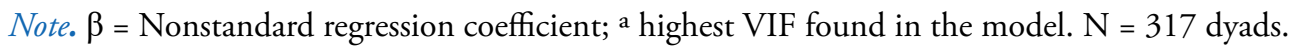

$a_{1}=\left(b_{1}+b_{2}\right)$, where $b_{1}$ is the beta coefficient for buyers' personal values and $b_{2}$ is the beta coefficient for sellers' personal values. $a_{2}=\left(b_{3}+b_{4}+b_{5}\right)$, where $b_{3}$ is the beta coefficient for the buyers' personal values squared, $b_{4}$ is the beta coefficient for the product of the multiplication between the buyers' personal values and the sellers' personal values and $b_{5}$ is the beta coefficient for the sellers' personal values squared. $a_{3}=\left(b_{1}-b_{2}\right) \cdot a_{4}=\left(b_{3}-b_{4}+b_{5}\right)$.

${ }^{* *} p<.01 ;{ }^{*} \mathrm{p}<.05$

The response surfaces in Figure 2 illustrate the level of the dependent variable (relationship value) on the response surface when two independent variables are combined (personal values of buyers $[\mathrm{X}]$ and personal values of sellers $[\mathrm{Y}])$. The graphs are generated with the non-standard regression coefficients (Table 3) and the equations described in Appendix A. 

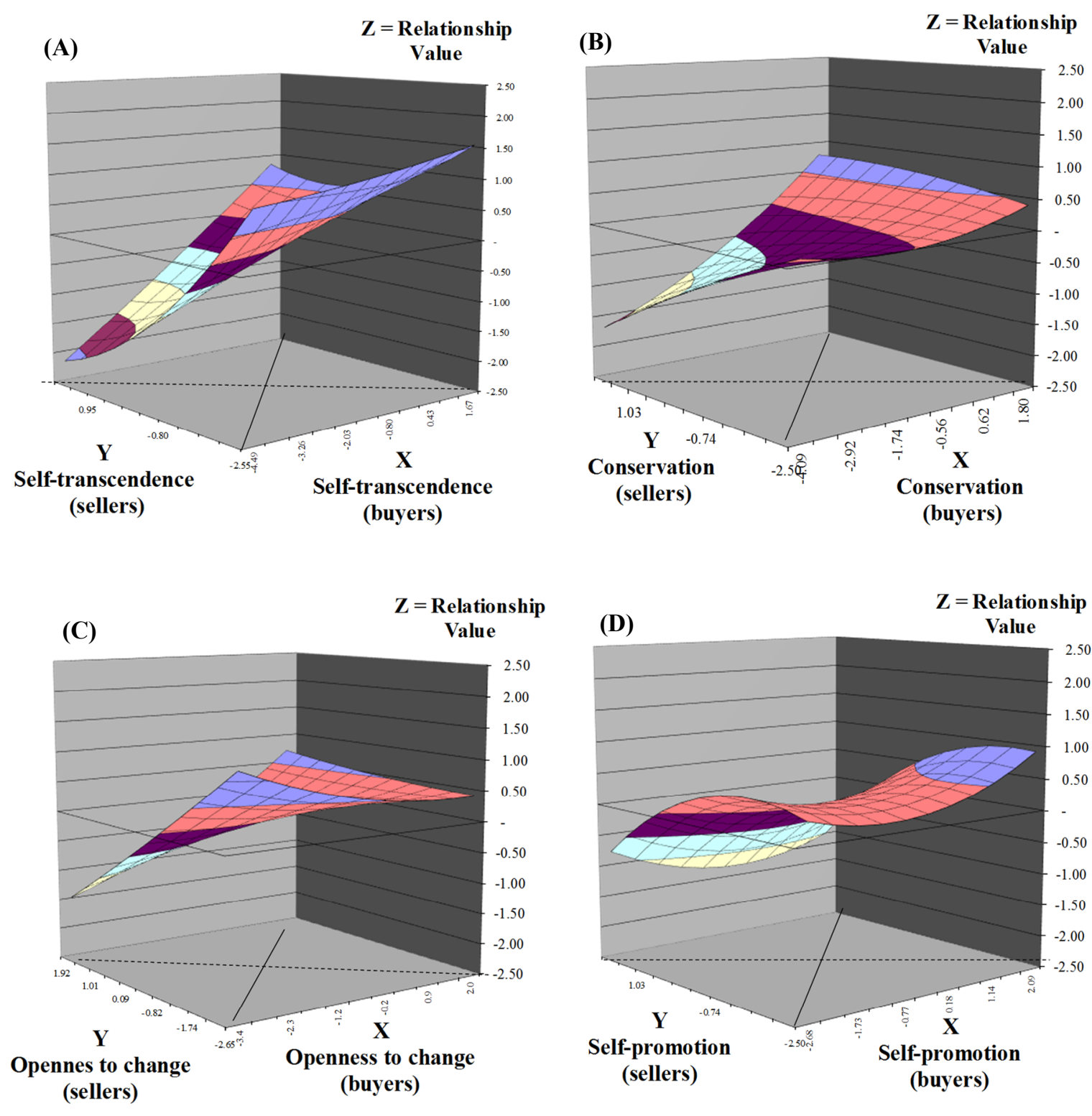

Figure 2. Response Surface Graphs

Source: Developed by the authors.

Figure $2 \mathrm{~A}$ shows that the symmetry line where the combination between the buyer and seller's self-transcendence is high, the $\mathrm{Z}$ axis (relationship value) is also high. However, when analyzing the dissimilarity along the asymmetry line, it is noted that the relationship value is greater when the Buyer's Self-transcendence is high and the Seller's Self-transcendence is low. The effects of the symmetry and asymmetry line in Figure $2 \mathrm{~B}$ are similar to Figure 2A, which indicates that the similarity between the Conservation values of buyers and sellers has a positive effect on the relationship value, but when there is dissimilarity, the relationship value is higher when the Conservation of the buyer is high and the seller is low. Figure 2D shows that on the symmetry line, where the combination between the buyer and seller's self-promotion are high, the $\mathrm{Z}$ axis (relationship value) is low. However, when analyzing the dissimilarity along the asymmetry line, it is noted that the relationship value is greater when the Buyer's Self-promotion is high and the Seller's Self-promotion is low. 
In addition, Figures $2 \mathrm{~A}$ and $2 \mathrm{C}$ and Table 3 show a U-shaped curvilinear effect for the symmetry line (i.e., similarity) between Self-transcendence values $\left(a_{2}: .13 ; \mathrm{p}<.05\right)$, and Open to changes $\left(a_{2}: .14 ; \mathrm{p}<.05\right)$ of the buyer and seller. These results indicate a marginal effect not described in our hypotheses. The congruence value literature provides a plausible explanation for these unexpected results (Byza et al., 2019). The congruence of values in which two individuals have strong beliefs (for example, they consider an extremely important or extremely unimportant value) is more strongly related to the behavioral results of these individuals than the congruence in values in which these individuals have moderate beliefs (Edwards \& Cable, 2009). This indicates that, for a similarity of value between partners to have an effect on people's actions, only similarities of values at their ends will indicate whether the people involved in the relationship will act according to their values (Byza et al., 2019).

Thus, for the similarity of Self-transcendence and Openness to change to have an effect on the relationship value, these values must be extremely high on both sides (buyer and seller attach great importance to these values) or extremely low (buyer and seller attribute little importance to these values). A moderate expression of these values will not allow for further adjustment (Verquer et al., 2003), as it will not provide clarity that both share common aspects of cognitive processing and common methods of interpreting events (Ostroff et al., 2005). As a result, the effects of similarity between Self-transcendence and Openness to changes at moderate levels impair the perceived value of the buyer's relationship.

\section{DISCUSSION}

The similarity and dissimilarity of the personal values of the seller-buyer dyad operate differently in the opposite dimensions of a social focus (Self-transcendence and Conservation) and those of a personal focus (Openness to Change and Self-Promotion).

The dimensions of social focus include values of tolerance and understanding, of respect and acceptance, of concern for the well-being of people who are close and of the stability and harmony of relationships (Schwartz et al., 2012). When the seller and the buyer engage in a commercial exchange, and have these same values values, the perception that the benefits are more than the sacrifices involved (Eggert et al., 2006) is generated with the buyers. The dimensions of social focus also include values of protection, preservation, commitment, fulfillment of expectations and security (Schwartz et al., 2012). Therefore, even in the absence of these personal social values on the part of the seller, the valorization of collaborative relationships (Self-transcendence) and maintenance of the status quo (Conservation) on the part of the buyer (scenario in which the values of the buyers are high and of the sellers are low), the relationship value will be perceived as being valuable to the buyer. However, when the seller tries to create a relationship with a buyer that does not have a social focus (a scenario in which the buyers' values are low and sellers are high), the seller may end up wearing down the commercial and personal life between them, leaving the buyer uncomfortable and pressured, resulting in a lower perception of the benefits of the relationship.

In contrast to the dimensions of a social focus, personal focus values reflect the concern for oneself. Self-promotion values are more related to self-satisfaction than to the relationship as a whole (Schwartz et al., 2012). This reflects the results found, that the similarity between the buyer and seller's self-promotion affects the relationship value in a negative way. This indicates that, when a seller has values that indicate a search for status, prestige, and personal success (Schwartz et al., 2012), the value perceived by the buyer tends to be lower. That is, the dispute for autonomy, the need to control people and resources, and the need to demonstrate competence (Schwartz et 
al., 2012), manifested by the seller compromises the relationship, which reflects in a decrease of value perceived by the buyer. However, when only the buyer has high Self-promotion, and the seller does not express a belief in this value, there will probably be no conflicts in the relationship, generating a positive perception of value in the relationship.

The results, therefore, corroborate in part with the conclusions that similarity is beneficial for theperceived value of a B2B relationship, and confirms the thesis that the dissimilarity of personal values is unfavorable to the value of the $\mathrm{B} 2 \mathrm{~B}$ relationship when the seller expresses strong belief in personal values but the buyer does not share the same belief.

\section{CONCLUSIONS}

\subsection{TheOretical CONTRIBUTIONS}

We contribute to the literature in two main aspects. First, in relation to B2B relationship marketing, we analyze how the values of individuals involved in commercial exchanges can influence perceived relationship value between companies. Previous studies have already investigated the role of other relationship variables (Skarmeas et al., 2018; De Toni et al., 2015) or personal interactions (Hohenschwert \& Geiger, 2015) in the value of relationships in B2B markets. But research that investigates the effect of personal values on the perceived value of a relationship between companies is scarce. Furthermore, in the marketing literature, similarity is usually studied by the similarity between organizational values in the investigations of relationships between companies (Wang \& Zhang, 2017), or by the alignment between the values of employees and leaders (Byza et al., 2019) and between organizational values and employee values in intraorganizational research (Kashyap \& Sivadas, 2012). As far as we know, our research is the first to assess the relationship between companies from the perspective of the similarity between the personal values of the individuals involved in these relationships.

Second, we shine a light on the similarity-attraction theory. Using the grounded theory of Schwartz et al. (2012) that there is a distinction between social focus values and personal focus values, and that these dimensions are positioned in opposite sides of the continuum (i.e., an individual almost never holds opposite values), we argue that the idea that similarity always promotes harmony in relationships (e.g., Zhang \& Bloemer, 2008) can be mistaken, at least in the B2B context. Our results demonstrate that, just as social focus values can contribute to a greater perception of value in the relationship, there is also a contrary side where thesimilarity between personal focus values can harm the perceived value, and possibly other relationship variables.

\subsection{Managerial implications}

The empirical importance of the study is related to the establishment of interpersonal relationships with a view to the greater performance of companies. In the surveyed dyad, conservative farmers (i.e., a predominant resale audience) avoid changes, and prefer to feel safe and stable in their relationships, which can impact the resale performance, since a salesperson's average working time is only a little longer than six years. If the buyer has social focus values, the values of the salesperson are less important, since both similarity and dissimilarity are beneficial to the Relationship value. But, if the buyer has a more personal focus, the more opposite the salespeople can be, the greater the perceived value of the farmers in regards to the relationship. Therefore, sales teams can be adjusted in relation to the values of their buyers, either through the replacement of current salespeople, or in the selection of new salespeople. 
BBR

18

292

In general, companies that supply products and services in B2B markets must be attentive to the personal characteristics of salespeople, not only to similarities in relation to their buyers, but also to the dissimilarities. These results have primary implications for the concepts of strategic marketing planning, from the structuring of the company to the selection of the target market to be served and the form of segmentation adopted.

\subsection{Limitations and Future Research}

The results cannot be generalized and, therefore, other studies must be developed with the variables and the method used, in order to consolidate the proposed theory. As farmers have both personal and organizational characteristics, the effects of Personal Values on the relationship can vary according to the researched dyad.

An interesting form of research would be to understand the impact or mediation of the values similarity in the relationship between the Relationship value and other performance variables, which was not incorporated in this research due to the complexity of the current model. Future research can also test what the effect of the similarity of opposite value dimensions on the relationship value, such as, for example, the impact that similarity between the seller's Self-transcendence and the Buyer's Self-promotion has, for example, on the relationship value.

\section{REFERENCES}

Alejandro, T. B., Souza, D. V., Boles, J. S., Ribeiro, Á. H. P., \& Monteiro, P. R. R. (2011). The outcome of company and account manager relationship quality on loyalty, relationship value and performance. Industrial Marketing Management, 40(1), 36-43. https://doi.org/10.1016/j. indmarman.2010.09.008

Arieli, S., Sagiv, L., \& Roccas, S. (2020). Values at work: The impact of personal values in organisations. Applied Psychology, 69(2), 230-275. https://doi.org/10.1111/apps.12181

Arslanagic-Kalajdzic, M., \& Zabkar, V. (2015). The external effect of marketing accountability in business relationships: Exploring the role of customer perceived value. Industrial Marketing Management, 46, 83-97. https://doi.org/10.1016/j.indmarman.2015.03.002

Blocker, C. P., Flint, D. J., Myers, M. B., \& Slater, S. F. (2011). Proactive customer orientation and its role for creating customer value in global markets. Journal of the Academy of Marketing Science, 39(2), 216-233. https://doi.org/10.1007/s11747-010-0202-9

Byrne, D. (1971). The Attraction paradigm. Academic Press: New York.

Byza, O. A. U., Dörr, S. L., Schuh, S. C., \& Maier, G. W. (2019). When leaders and followers match: The impact of objective value congruence, value extremity, and empowerment on employee commitment and job satisfaction. Journal of Business Ethics, 158(4), 1097-1112. https://doi. org/10.1007/s10551-017-3748-3

Cable, D. M., \& Edwards, J. R. (2004). Complementary and supplementary fit: a theoretical and empirical integration. Journal of Applied Psychology, 89(5), 822. https://doi.org/10.1037/00219010.89 .5 .822

Campbell, W. K., Reeder, G. D., Sedikides, C., \& Elliot, A. J. (2000). Narcissism and comparative selfenhancement strategies. Journal of Research in Personality, 34(3), 329-347. https://doi.org/10.1006/ jrpe.2000.2282 
Cropper, S., Ebers, M., Huxham, C., \& Ring, P. S. (2014). Handbook de relaçóes interorganizacionais da Oxford. Porto Alegre: Bookman.

De Toni, D., Milan, G. S., Costa, G. C., \& Larentis, F. (2015). Existing relational practice between a manufacturer and its distributors and the perception of the relationship value in the dyad. Brasilian Business Review, 12(6), 48-71. https://doi.org/10.15728/bbr.2015.12.6.3

Edwards, J.R., \& Cable, D.M. (2009). The value of value congruence. Journal of Applied Psychology, 94(3), 654-677. https://doi.org/10.1037/a0014891

Edwards, J. R., \& Parry, M. E. (1993). On the use of polynomial regression equations as an alternative to difference scores in organizational research. Academy of Management Journal, 36(6), 1577-1613. https://doi.org/10.5465/256822

Eggert, A., \& Ulaga, W. (2002). Customer perceived value: A substitute for satisfaction in business markets? Journal of Business \& Industrial Marketing, 17(2/3), 107-118. https://doi. org/10.1108/08858620210419754

Eggert, A., Ulaga, W., \& Schultz, F. (2006). Value creation in the relationship life cycle: A quasilongitudinal analysis. Industrial Marketing Management, 35(1), 20-27. https://doi.org/10.1016/j. indmarman.2005.07.003

Faia, V.S., Negreiros, L.F., Vieira, V.A. (2019). Polynomial Regression and Response Surface Analysis using SPSS. Publisher: Autor. ISBN: 9781703428353

Grewal, R., G. L., Bharadwaj, S., Jindal, P., Kayande, U., Lusch, R. F., Mantrala, M., Palmatier, R. W., Rindfleisch, A., Scheer, L. K., Spekman, R., \& Sridhar, S. (2015). Business-to-Business Buying: Challenges and Opportunities. Customer Needs and Solutions, 2(3), 193-208. https://doi. org/10.1007/s40547-015-0040-5

Hair, J. F, Black, W. C., Babin, B. J., Anderson, R. E., \& Tatham, R. L. (2009). Multivariate data analysis (6a ed.). Upper Saddle River: Pearson Prentice Hall.

He, J., Huang, H., \& Wu, W. (2018). Influence of interfirm brand values congruence on relationship qualities in B2B contexts. Industrial Marketing Management, 72, 161-173. https://doi.org/10.1016/j. indmarman.2018.02.015

Hohenschwert, L., \& Geiger, S. (2015). Interpersonal influence strategies in complex B2B sales and the socio-cognitive construction of relationship value. Industrial Marketing Management, 49, 139-150. https://doi.org/10.1016/j.indmarman.2015.05.027

Kashyap, V., \& Sivadas, E. (2012). An exploratory examination of shared values in channel relationships. Journal of Business Research, 65(5), 586-593. https://doi.org/10.1016/j.jbusres.2011.02.008

Krystallis, A., Vassallo, M., \& Chryssohoidis, G. (2012). The usefulness of Schwartz's 'Values Theory' in understanding consumer behaviour towards differentiated products. Journal of Marketing Management, 28(11-12), 1438-1463. https://doi.org/10.1080/0267257X.2012.715091

Lalwani, A. K., \& Shavitt, S. (2009). The "me” I claim to be: Cultural self-construal elicits selfpresentational goal pursuit. Journal of Personality and Social Psychology, 97(1), 88. https://doi. org/10.1037/a0014100

Lilien, G. L. (2016). The B2B Knowledge Gap. International Journal of Research in Marketing, 33(3), 543-556. https://doi.org/10.1016/j.ijresmar.2016.01.003

Manosso, T. W. S., \& Antoni, V. L. (2018). Da congruência de valor entre boundary spanners à satisfação em mercados B2B: uma perspectiva teórica. Revista Alcance, 25(2), 194-210. 
BBR

18

294
Ostroff, C., Shin, Y., \& Kinicki, A. J. (2005). Multiple perspectives of congruence: Relationships between value congruence and employee attitudes. Journal of Organizational Behavior: The International Journal of Industrial, Occupational and Organizational Psychology and Behavior, 26(6), 591-623. https://doi.org/10.1002/job.333

Palmatier, R. W., Dant, R. P., Grewal, D., \& Evans, K. R. (2006). Factors influencing the effectiveness of relationship marketing: a meta-analysis. Journal of Marketing, 70, 136-153. https://doi. org/10.1509/jmkg.70.4.136

Prado, L. S., \& Martinelli, D. P. (2018). Analysis of negotiation strategies between buyers and sellers: an applied study on crop protection products distribution. RAUSP Management Journal, 53(2), 225-240. https://doi.org/10.1016/j.rauspm.2018.01.001

Qu, Y. E., Dasborough, M. T., Zhou, M., \& Todorova, G. (2017). Should authentic leaders value power? A study of leaders' values and perceived value congruence. Journal of Business Ethics, 1-18. https://doi.org/10.1007/s10551-017-3617-0

Rokeach, M. (1973). The nature of human values. New York: Free Press.

Sabbir, R.M. \& Nazrul, I. (2014). Value congruence and consumer's satisfaction towards online banking - the mediation role of affective commitment. Management \& Marketing, 9(3), 347-358.

Schwartz, S. H. (1992). Universals in the content and structure of values: Theoretical advances and empirical tests in 20 countries. Advances in experimental social Psychology, 25(1), 1-65. https://doi. org/10.1016/S0065-2601(08)60281-6

Schwartz, S. H., Cieciuch, J., Vecchione, M., Davidov, E., Fischer, R., Beierlein, C., Ramos, A., Verkasalo, M., Lönnqvist, J.-E., Demirutku, K., Dirilen-Gumus, O., \& Konty, M. (2012). Refining the theory of basic individual values. Journal of Personality and Social Psychology, 103(4), 663-688. https://doi.org/10.1037/a0029393

Sirgy, M. J. (1982). Self-concept in consumer behavior: A critical review. Journal of Consumer Research, 9(3), 287-300. https://doi.org/10.1086/208924

Skarmeas, D., Saridakis, C., \& Leonidou, C. N. (2018). Examining relationship value in cross-border business relationships: A comparison between correlational and configurational approaches. Journal of Business Research, 89, 280-286. https://doi.org/10.1016/j.jbusres.2017.12.039

Torres, C. V., Schwartz, S. H., \& Nascimento, T. G. (2016). A Teoria de Valores Refinada: associaçóes com comportamento e evidências de validade discriminante e preditiva. Psicologia USP, 27(2), 341-356. http://dx.doi.org/10.1590/0103-656420150045

Ulaga, W., \& Eggert, A. (2006). Relationship value and relationship quality: Broadening the nomological network of business-to-business relationships. European Journal of Marketing, 40(3-4), 311-327. https://doi.org/10.1108/03090560610648075

Verquer, M. L., Beehr, T. A., \& Wagner, S. H. (2003). A meta-analysis of relations between personorganization fit and work attitudes. Journal of Vocational Behavior, 63(3), 473-489. https://doi. org/10.1016/S0001-8791(02)00036-2

Wang, J. J., \& Zhang, C. (2017). The impact of value congruence on marketing channel relationship. Industrial Marketing Management, 62, 118-127. https://doi.org/10.1016/j.indmarman.2016.08.004

Wilson, K. S., DeRue, D. S., Matta, F. K., Howe, M., \& Conlon, D. E. (2016). Personality similarity in negotiations: Testing the dyadic effects of similarity in interpersonal traits and the use of emotional displays on negotiation outcomes. Journal of applied psychology, 101(10), 1405-1421. https://doi.org/10.1037/apl0000132 
Zhang, J., \& Bloemer, J. M. (2008). The impact of value congruence on consumer-service brand relationships. Journal of Service Research, 11(2), 161-178. https://doi.org/10.1177/1094670508322561

Zhu, D. H., \& Chang, Y. P. (2013). Negative publicity effect of the business founder's unethical behavior on corporate image: evidence from China. Journal of Business Ethics, 117(1), 111-121. https://doi.org/10.1007/s10551-012-1512-2

\section{AUTHOR'S CONTRIBUTION}

TM was responsable for Conceptualization, Data curation, Formal analysis, Research, Methodology, Resources, Software and Writing of the original draft; JS treated of Data curation, Formal analysis, Research, Methodology, Software, Review and editing; VA collaborated with Project management, Supervision, Validation, Review and editing; and CD Supervised, Validated, Revised and edited the paper.

\section{FINANCIAL SUPPORT}

This work was carried out with the support of the Coordination for the Improvement of Higher Education Personnel - Brazil (CAPES) - financing code 001.

\section{CONFLICTS OF INTEREST}

The authors declare that there is no conflict of interest in the publication of this research. 
An ASR is recommended when performing simultaneous tests of effects, such as values similarity (Edwards \& Parry, 1993). The coefficients generated by the polynomial regression equation describes how two variables (for example, Self-transcendence of the buyer and Self-transcendence of the seller) are related together with the outcome variables based on surface response techniques.

Specifically, the relationship between component X (e.g., buyer's self-transcendence), Y (e.g., seller's self-transcendence) and the outcome variable $Z$ (e.g., relationship value) can be written as:

$$
Z=\beta_{0}+\beta_{1} \chi+\beta_{2} \gamma+\beta_{3} \chi^{2}+\beta_{4} \chi \gamma+\beta_{5} \gamma^{2}+e .
$$

To test whether the outcome variable varies along the line where the personal values of buyers and sellers are similar, we model the polynomial regression with $Y=X$. Replacing $Y=$ in Equation (1), the line for perfect symmetry is expressed as:

$$
Z=\beta_{0}+\left(\beta_{1}+\beta_{2}\right) \chi+\left(\beta_{3}+\beta_{4}+\beta_{5}\right) \chi^{2}+e .
$$

Therefore, the slope of the effect on the result is denoted by $\left(b_{1}+b_{2}\right)$ and, respectively, the curvature is $\left(b_{3}+b_{4}+b_{5}\right)$. If the curvature $\left(b_{3}+b_{4}+b_{5}\right)$ does not differ significantly from zero, but the slope does, the perfect symmetry line is linear. In such cases, a positive slope $\left(\left[b_{1}+b_{2}\right]>\right.$ 0 ) would indicate a linear increase in the result $(Z)$ as the magnitude of similar values increases. If the curvature is significantly positive $\left(b_{3}+b_{4}+b_{5}\right)>0$, the shape of the symmetry line values is U-shaped. On the other hand, if the curvature is significantly negative $\left(b_{3}+b_{4}+b_{5}\right)<0$, the line follows an inverted $U$ shape. In ASR, the regression coefficients of the equations are not directly interpreted, but are used to examine the response surface pattern. In the graph, the slopes of the symmetry and asymmetry lines are interpreted. For a more in-depth review, see Faia et al. (2019). 